lution und die Demokratisierung in El Salvador und Guatemala. Das ziemlich in Mitleidenschaft gezogene Costa Rica wird ebenso wie das militärisch zumindest mittelbar zwangsinvolvierte Honduras ausgespart, was für letzteres bedauern muß, wer immer wieder nach qualifizierten Informationen über Honduras sucht. Verdienstvoll wiederum, daß der Rolle der Kirche in der gegenwärtigen Entwicklung ein eigener Beitrag vorbehalten ist. Die sieben Einzelbeiträge des folgenden internationalen Teils widmen sich der vielfältigen Inolviertheit regionaler (Mexiko, Venezuela), interrregionaler (USA, Cuba) und extrakontinentaler (Warschauer Pakt, EG) Akteure.

Was dieses Buch aus der Masse der sonst verfügbaren Traktate zur Krise in Zentralamerika hebt, ist der durchgängig dominierende Realismus, der die US-Politik gegenüber den Isthmus-Staaten zwar auch keineswegs mit Samthandschuhen anfaßt, endogenen Krisenfaktoren aber ihr Eigengewicht beläßt. Was in dieser Region nottut - so das Fazit - sind vorrangig weniger dem Ost-West-Spektrum entlehnte Militär-Strategien, als vielmehr dem Nord-Süd-Dialog zugewandte Sozial-Strategien. Hier sind (wie könnte es anders sein) namentlich die westlichen Industriestaaten gefordert.

Karl-Andreas Hernekamp

\title{
Reinhard Gumbert
}

\section{Private Auslandsinvestitionen und Gewinntransfer nach brasilianischem Recht}

Schriftenreihe: Ausländisches Wirtschafts- und Steuerrecht, Band 60. X+135 S. Köln: Bundesstelle für Außenhandelsinformation, 1985

Die gründliche und sorgfältige Publikation behandelt vornehmlich jene brasilianischen Regeln, unter denen sich ausländisches Kapital betätigen darf. Sie schließt Investitionen, Darlehen, Importfinanzierungen und Technologie-Verträge ein.

Dem Verfasser, einem deutschen Rechtsanwalt, kommt seine Mitarbeit in einem bedeutenden brasilianischen Anwaltsbüro zustatten. Er kann deshalb, über die Rechtsnormen hinaus, auch die Realität des verwaltungsmäßigen Umgangs mit dem geschriebenen Recht darlegen. Nicht immer hält sich die brasilianische Praxis an die Hierarchie der Rechtsnormen: Verordnungen und Erlasse modifizieren zuweilen auf ihre Weise den Sinn von Gesetzen.

Wie sich zeigt, kann trotz gleichbleibender Rechtslage eine veränderte Handhabung nachträglich administrative Hemmnisse aufbauen. Neue Geschäftszweige bleiben dem einheimischen Kapital vorbehalten. Genehmigungen können verzögert oder versagt und Verkaufspreise ohne Rücksicht auf Kosten und Rentabilität eingefroren werden.

Wie anderenorts verändern der Druck der Verschuldung, die Konjunktur und die innenpolitische Lage auch Brasiliens Haltung zu den wirtschaftlichen Gegebenheiten.

Während man früher die Entwicklung leicht zu optimistisch einschätzte, droht jetzt das Umgekehrte, was genauso verfehlt wäre. Auch wenn sich seit dem Abschluß der vorlie- 
genden Arbeit Ende 1984 wieder manches geändert hat, verhilft eine solche Publikation zu einem ausgewogenen Urteil.

Hans Jolowicz

\section{Karin Bollmann}

\section{Massenmedien und Nachrichtengebung in Mexiko}

Eine empirische Analyse zum Spannungsverhältnis von staatlicher, privatwirtschaftlicher und transnationaler Einflußnahme. (Forschungen zu Lateinamerika Bd. 7). Saarbrücken, Fort Lauderdale 1986, S. 434, DM 49,--

Diese auf einem zweijährigen Forschungsaufenthalt 1980-1982 beruhende Dissertation faßt in einem umfangreichen Anhang wie auch in vielen Tabellen und Ubersichten lükkenlos die in Mexiko bestehenden Massenmedien zusammen, wie da sind Tagespresse, Rundfunk und Fernsehen sowie Nachrichtenagenturen. So werden etwa in der Úbersicht A-2 im Anhang die hauptstädtischen Tageszeitungen mit Titel, Untertitel, Gründungsdatum, Verlag, Gesellschaftsform, Angabe des Herausgebers und Hauptgeschäftsführers, Preis, Erscheinungsweise, Auflage und Verbindung zu Nachrichtenagenturen aufgeführt und auf S. $142 \mathrm{ff}$. näher untersucht. Die Intensität des hereingeholten Materials zeigt sich beispielsweise in der Wiedergabe der Monatsgehälter der Journalisten, S. 240, sowie der Anzeigenpreise von elf ausgewählten Tageszeitungen, S. 157. Akribisch werden die komplizierten Besitzverhältnisse bei den privaten Rundfunk- und Fernsehgesellschaften, allen voran Televisa, nachgezeichnet, S. $179 \mathrm{ff}$.

Von Interesse sind die vielfältigen Einflußversuche staatlicher Stellen auf die Massenmedien durch gezielte Lizenz- und Konzessionsvergaben, die Registrierung der Zeitungen und Zeitschriften als Voraussetzung für die Befreiung vom Porto, Zuteilung von Papier durch die PIPSA und plötzliche Schuldeneintreibung durch diese, Kreditvergabe durch die NAFINSA, Einfluß auf Journalistengewerkschaften, Inanspruchnahme von Sendezeiten, die die Rundfunkgesellschaften dem Staat zur Abgeltung von Steuerabgaben zur Verfügung stellen, Abdruck regierungsamtlicher Bulletins, Kanalisierung des Informationsflusses (so dargestellt im Falle Proceso im April 1982 durch López Portillo), Korrumpierung von Journalisten, gezielte Anzeigenplazierung und schließlich die reine Repressalie, allerdings kaum in der Hauptstadt, wohl aber in der Provinz, S. 308/9.

Auf S. 319 ff. befaßt sich B. mit dem in der Verfassung verankerten Recht auf Information (Art. 6). Ein derartiges staatlich gesichertes Recht wurde von der Privatwirtschaft als die Meinungsfreiheit potentiell beschränkend bekämpft. Die gutnachbarlichen Beziehungen zwischen dem staatlichen Fernsehkanal 13 und Televisa in der Amtsperiode López Portillo verhinderten einen stärkeren staatlichen Einfluß. Auch unter Präsident de la Madrid Hutardo änderte sich kaum etwas. Televisa war für die Úbertragung der Fußballweltmeisterschaft 1986 unentbehrlich.

Gerhard Scheffler 